\title{
Effect of Mg Deficiency on Antioxidant Enzymes Activities and Lipid Peroxidation
}

\author{
Ezatollahe Esfandiari (Corresponding author) \\ Department of Agronomy and Plant Breeding, Faculty of Agriculture \\ University of Maragheh, Maragheh, Iran \\ Tel: 98-421-227-3068 E-mail: esfand1977@yahoo.com \\ Majid Shokrpour \\ Department of Agronomy and Plant Breeding, Faculty of Agriculture \\ University of Mohaghegh Ardabili, Ardabil, Iran \\ Siamak Alavi-Kia \\ Department of Agronomy and Plant Breeding, Faculty of Agriculture \\ University of Tabriz, Tabriz, Iran
}

\begin{abstract}
The importance of the physiological role of nutrient elements in plant behavior concerning higher and more stable yield, using the durum wheat variety P1252 as model plant, was examined under hydroponic conditions. To investigate the effects of $\mathrm{Mg}$ deficiency, the element was eliminated from the media solutions. Results showed that $\mathrm{Mg}$ elimination decreased the chlorophyll content. Lack of $\mathrm{Mg}$ only affected guaiacol peroxidase (GPX) and catalase (CAT) activities significantly. The SOD/APX+GPX+CAT ratio as an index of assessing the balance between $\mathrm{H}_{2} \mathrm{O}_{2}$-producing and $\mathrm{H}_{2} \mathrm{O}_{2}$-scavenging enzymes increased leading to the accumulation of $\mathrm{H}_{2} \mathrm{O}_{2}$ in cell. The elevation of SOD/APX $+\mathrm{GPX}+\mathrm{CAT}$ ratio and $\mathrm{H}_{2} \mathrm{O}_{2}$ accumulation indicates the occurrence of oxidative stress in leave cells under $\mathrm{Mg}$ deficiency. -Lack of magnesium $(\mathrm{Mg})$ resulted in considerable increase in other oxidative stress indices, cell death and Malondialdehyde (MDA). The reason is the occurrence of Haber-Weiz reaction in absence of $\mathrm{Mg}$ and production of hydroxyl radical, a very dangerous radical, leading to increasing damage of cell biomolecules and their apoptosis.
\end{abstract}

Keywords: Mg deficiency, Oxidative stress, ROS Scavenging

\section{Introduction}

Crops are often exposed to various types of stresses including deficiencies during their life time. Due to various roles of nutrient in plant cells, their deficiency may lead to metabolic disorders. The reason is that an element such as $\mathrm{Mg}$, a macro-nutrient element, hold a critical role in activation of some important enzymes such as ATPases, ribulose 1, 5-bisphosphate (RuBP) carboxylase, RNA polymerase and protein kinases (Cakmak and Kirkby, 2008). Mg holds a fundamental role in phloem export of photosynthates from photosynthetic organs to roots. $\mathrm{Mg}$ deficiency results in dramatic increases in carbohydrates accumulation of source leaves (Hermans et al., 2004), leads to reduced transport and accumulation of carbohydrates, alters photosynthetic carbon metabolism and restricts $\mathrm{CO}_{2}$ fixation. Impairment of the photosynthetic electron transport to $\mathrm{CO}_{2}$ through photosynthetic membranes may cause an accumulation of non-utilized electrons and absorbed energy (Hermans and Verbruggen, 2005). Moreover, Mg deficiency decreases pore conductivity (Velikova et al., 2000). Under such conditions, the electrons and excited energy that not used in photosynthetic $\mathrm{CO}_{2}$ fixations are channeled to molecular $\mathrm{O}_{2}$, leading to produce reactive oxygen species (ROS). ROS are regarded as one of the main sources of cell damages under biotic and abiotic stresses (Mittler, 2002). ROS are partially reduced forms of atmospheric oxygen which are produced in vital processes such as photorespiration, photosynthesis and respiration (Esfandiari et al., 2007; Jimenez et al., 1998; Mittler, 2002; Kornyeyev, et al., 2003; Vaidyanathan et al., 2003; Uchida et al., 2002).

For production of water in these processes, four electrons are required to full reduction of oxygen. ROS typically result from the transfer of one, two and three electrons to $\mathrm{O}_{2}$ in order to formation of superoxide $\left(\mathrm{O}_{2}^{-}\right)$, hydrogen peroxide $\left(\mathrm{H}_{2} \mathrm{O}_{2}\right)$ and hydroxyl radical ( $\left.\mathrm{HO}^{\circ}\right)$, respectively (Mittler, 2002). These species of oxygen are highly 
cytotoxic and can seriously react with vital biomolecules (i.e. lipids, proteins, nucleic acids, etc.) causing lipid peroxidation, protein denaturing and DNA mutation, respectively (Breusegem et al., 2003; Quiles and López, 2004; Scandalios, 1993). Evidence suggests that membranes are one the primary sites of cells and organelles injuries (Candan and Tarhan, 2003). This is because ROS can react with unsaturated fatty acids to cause peroxidation of essential membrane lipids in plasmalemma or intracellular organelles (Karabal et al., 2003). Peroxidation of plasmalemma leads to the leakage of cellular contents, rapid desiccation and cell death. Intracellular membrane damage can affect respiratory activity in mitochondria, eatsing pigment deterioration and loss of the carbon fixing ability in chloroplasts (Scandalios, 1993).

Nevertheless, plants have evolved various protective mechanisms to eliminate or reduce ROS, which are effective at different levels of stress-induced deterioration (Beak and Skinner, 2003). Enzymatic antioxidant system is one of the protective mechanisms including superoxide dismutase (SOD: EC 1.15.1.1) which can be found in various cell compartments and catalyses the disproportionate concentration of two $\mathrm{O}_{2}{ }^{-}$radicals to $\mathrm{H}_{2} \mathrm{O}_{2}$ and $\mathrm{O}_{2}$ (Scandalios, 1993). $\mathrm{H}_{2} \mathrm{O}_{2}$ is eliminated by various antioxidant enzymes such as catalases (CAT: EC 1.11.1.6) (Kono and Fridovich, 1983) and peroxidases (POX: EC 1.11.1.7) (Gara et al., 2003) which convert $\mathrm{H}_{2} \mathrm{O}_{2}$ to water. Other enzymes that are very important in ROS scavenging system and function in ascorbate-glutathione cycle are glutathione reductase (GR: EC1.6.4.2), monodehydro ascorbate reductase (MDHAR: EC 1.6.5.4) and dehydroascorbate reductase (DHAR: EC 1.8.5.1) (Candan and Tarhan, 2003).

Moreover, ROS are inevitable by-products of normal cell metabolism (Martinez et al., 2001). But under normal conditions production and destruction of ROS are well regulated in cell metabolism (Mittler, 2002). When a plant is encountered with harsh conditions, ROS production will overcome scavenging systems and consequently oxidative stress will dominate.

Knowing the physiological significance of nutrient elements in plant is one of the critical issues to improve the yield and yield stability. Regarding the magnesium key role in activating important enzymes such as RuBP-carboxylase, ATPases, Mg chelatase and allocation of photosynthetic compounds to shoot and root the present study was designed to assess Mg deficiency effects on plant metabolism considering some physiological parameters.

\section{Materials and Methods}

In order to study of $\mathrm{Mg}$ deficiency effects on activity of antioxidant enzymes, oxidative stress indexes (malondialdehyde contents (MDA) and $\mathrm{H}_{2} \mathrm{O}_{2}$ ) and cell death, the $\mathrm{P} 1252$ variety of durum wheat was planted in hydroponic way under controlled conditions. Nutrients used during growth period included macroelements $\left(\mathrm{Ca}\left(\mathrm{NO}_{3}\right)_{2}, \mathrm{KNO}_{3}, \mathrm{MgSO}_{4}\right.$ and $\mathrm{KH}_{2} \mathrm{PO}_{4}$ with concentrations of 3, 2.5, 1.5 and $0.17 \mathrm{mM}$, respectively) and microelements $\left(\mathrm{FeSO}_{4}, \mathrm{H}_{3} \mathrm{Bo}_{3}, \mathrm{MnSO}_{4}, \mathrm{ZnSO}_{4}, \mathrm{CuSO}_{4}\right.$ and $\mathrm{H}_{2} \mathrm{MoO}_{4}$ with concentrations 50,23, 5, 0.4, 0.2 and $0.1 \mu \mathrm{m}$, respectively). $\mathrm{MgSO}_{4}$ was eliminated from media solution in without $\mathrm{Mg}$ treatment (Grieve and Garttan, 1983).

The seedlings were planted on half strength nutrition solution till 2-3 leaves stage, then after they were nourished with full strength nutrient solution. The solutions were renewed twice a week to maintain the balance of nutrients concentration. $\mathrm{pH}$ of solutions were set around 5.2-5.5. Temperature, day length and light density were $25 \pm 2^{\circ} \mathrm{C}$, $14 \mathrm{~h}$ and $200 \mu \mathrm{M}$ photon $\mathrm{m}^{-2} \mathrm{~s}^{-1}$, respectively. The seedlings were grown under these conditions for two months. Sampling was made from completely-expanded leaves (zadoks scale, 18-19) and the plant materials were immediately transferred to liquid nitrogen and maintained at $-20^{\circ} \mathrm{C}$ until the measurement of variables under study. To measure the enzyme activity at least 5 leaves samples were used. Comparing the two levels of $\mathrm{Mg}$ (control and $\mathrm{Mg}$ deficiency) were done by t- student test.

\section{Measurement of antioxidant enzymes activities and other parameters:}

Enzyme extraction: For SOD, CAT and GR extraction, leaf samples $(0.5 \mathrm{~g})$ were homogenized in ice cold $0.1 \mathrm{M}$ phosphate buffer ( $\mathrm{pH} 7.5$ ) containing $0.5 \mathrm{mM}$ EDTA with pre-chilled pestle and mortar. Each homogenate was transferred to centrifuge tubes and was centrifuged at $4{ }^{\circ} \mathrm{C}$ in Beckman refrigerated centrifuge for 15 min at $15,000 \times \mathrm{g}$. The supernatant was used for enzyme activity assay.

For APX extraction, leaf samples $(0.5 \mathrm{~g})$ were homogenized in ice cold $0.1 \mathrm{M}$ phosphate buffer $(\mathrm{pH} 7.5)$ containing $0.5 \mathrm{mM}$ EDTA, $2 \mathrm{mM}$ ascorbate (AsA) and $5 \%$ poly vinyl pyrrolidin (PVP) with pre-chilled pestle and mortar. Other stages were similar to extraction of other enzymes (Esfandiari et al., 2007).

\section{Enzyme activity assay:}

SOD activity was estimated by recording the decrease in absorbance of superoxide-nitro blue tetrazolium complex by the enzyme (Sairam et al., 2002). About $3 \mathrm{ml}$ of reaction mixture, containing $0.1 \mathrm{ml}$ of $200 \mathrm{mM}$ 
methionine, $0.01 \mathrm{ml}$ of $2.25 \mathrm{mM}$ nitro-blue tetrazolium (NBT), $0.1 \mathrm{ml}$ of $3 \mathrm{mM}$ EDTA, $1.5 \mathrm{ml}$ of $100 \mathrm{mM}$ potassium phosphate buffer, $1 \mathrm{ml}$ distilled water and $0.05 \mathrm{ml}$ of enzyme extraction, were taken in test tubes in duplicate from each enzyme sample. Two tubes without enzyme extract were taken as control. The reaction was started by adding $0.1 \mathrm{ml}$ riboflavin $(60 \mu \mathrm{M})$ and placing the tubes below a light source of two $15 \mathrm{~W}$ florescent lamps for $15 \mathrm{~min}$. Reaction was stopped by switching off the light and covering the tubes with black cloth. Tubes without enzyme developed maximal color. A non-irradiated complete reaction mixture which did not develop color served as blank. Absorbance was recorded at $560 \mathrm{~nm}$ and one unit of enzyme activity was taken as the quantity of enzyme which reduced the absorbance reading of samples to $50 \%$ in comparison with tubes lacking enzymes.

CAT activity was measured according to Aebi (1984). About $3 \mathrm{ml}$ reaction mixture contained $1.5 \mathrm{ml}$ of $100 \mathrm{mM}$ potassium phosphate buffer ( $\mathrm{pH} 7$ ), $0.5 \mathrm{ml}$ of $75 \mathrm{mM} \mathrm{H} 2 \mathrm{O} 2,0.05 \mathrm{ml}$ enzyme extract and distilled water to make up the volume to $3 \mathrm{ml}$. Reaction started by adding $\mathrm{H} 2 \mathrm{O} 2$ and decrease in absorbance was recorded at $240 \mathrm{~nm}$ for $1 \mathrm{~min}$. Enzyme activity was computed by calculating the amount of $\mathrm{H} 2 \mathrm{O} 2$ decomposed.

APX activity was measured according to Yoshimura et al. (2000) by monitoring the rate of ascorbate oxidation at $290 \mathrm{~nm}\left(\mathrm{E}=2.8 \mathrm{mM}^{1} \mathrm{~cm}^{-1}\right)$. The reaction mixture contained $25 \mathrm{mM}$ phosphate buffer $(\mathrm{pH}=7), 0.1 \mathrm{mM}$ EDTA, $1 \mathrm{mM} \mathrm{H} 2 \mathrm{O} 2,0.25 \mathrm{mM}$ AsA and the enzyme sample. No change in absorption was found in the absence of AsA in the test medium.

Protein content of samples was determined by the method of Bradford (1976), bovine serum albumin used as a standard.

Peroxidation product estimation: Malondialdehyde (MDA) was measured by colorimetric method. $0.5 \mathrm{~g}$ of leaf samples were homogenized in $5 \mathrm{ml}$ of distilled water. An equal volume of $0.5 \%$ thiobarbituric acid (TBA) in $20 \%$ trichloroacetic acid solution was added and the sample incubated at $95^{\circ} \mathrm{C}$ for $30 \mathrm{~min}$. The reaction stopped by putting the reaction tubes in an ice bath. The samples were then centrifuged at $10000 \times \mathrm{g}$ for $30 \mathrm{~min}$. The supernatant was removed, absorption read at $532 \mathrm{~nm}$, and the amount of nonspecific absorption at $600 \mathrm{~nm}$ read and subtracted from this value. The amount of MDA present was calculated from the extinction coefficient of $155 \mathrm{mM}^{-1} \mathrm{~cm}^{-1}$ (Stewart and Bewley, 1980).

Determination of $\mathbf{H}_{2} \mathbf{O}_{2}$ content: Hydrogen peroxide levels were determined according to Sergive et al., (1997). Leaf tissues $(0.5 \mathrm{~g})$ were homogenized in ice bath with $5 \mathrm{ml} 0.1 \%(\mathrm{w} / \mathrm{v})$ TCA. The homogenate was centrifuged at $12000 \times \mathrm{g}$ for $15 \mathrm{~min}$ and $0.5 \mathrm{ml}$ of the supernatant was added to $0.5 \mathrm{ml} 10 \mathrm{mM}$ potassium phosphate buffer $(\mathrm{pH}=7.0)$ and $1 \mathrm{ml} 1 \mathrm{M} \mathrm{KI}$. The absorbancy of supernatant was read at $390 \mathrm{~nm}$. The content of $\mathrm{H} 2 \mathrm{O} 2$ was given on standard curve.

Determination of cell death: Aliquots consisting of four leaf discs were removed from treatments and submerged in $1 \mathrm{ml}$ of $0.25 \%$ Evans blue in $10 \mathrm{ml}$ disposable plastic beakers and incubated on a platform shaker at $80 \mathrm{rpm}$ for $20 \mathrm{~min}$. the beaker contents were poured into a small Buchner funnel and the discs rinsed well with deionized water until no more blue stain was eluted. The discs were ground with using a pestle and the homogenate diluted with $0.5 \mathrm{ml}$ of deionozed water. The tube was capped, vortexed and centrifuged at $10000 \times \mathrm{g}$ for $5 \mathrm{~min}$. A $0.8 \mathrm{ml}$ aliquot of the supernatant was removed and the optical density determined spectrophotometrically at $600 \mathrm{~nm}$ (Baker and Mock, 1994).

\section{Results and discussion}

Results indicated that chlorophyll content has been affected by Mg deficiency (Fig. 1). GPX and CAT activity had significant decrease compared to control under lack-of-Mg conditions (Figs 2 and 3). Whilst the other $\mathrm{H}_{2} \mathrm{O}_{2}$ scavenger activity, APX, did not display any change compared to control (Fig. 4). Moreover, the activity of $\mathrm{H}_{2} \mathrm{O}_{2}$ producer enzyme, SOD, did not significantly increase in the Mg-deficit condition (Fig. 5). Observing the balance of the enzyme which produces $\mathrm{H}_{2} \mathrm{O}_{2}$ (SOD) and its scavenging enzyme (APX, GPX and CAT) showed that lack of Mg may disrupt the balance. Because of the decrease in the scavenger enzymes activity, the ratio had a significant and considerable growth (\%352.29-Fig. 6).

The results showed that, $\mathrm{H}_{2} \mathrm{O}_{2}$ accumulated at in wheat seedling under $\mathrm{Mg}$ deficiency regime (Fig. 7). The lack of Mg increased MDA content (Fig. 8) and cell death significantly comparing with control (Fig. 9).

The results indicated $\mathrm{H}_{2} \mathrm{O}_{2}$ accumulation under $\mathrm{Mg}$ deficiency conditions because, it is an essential element has a critical role in cell metabolism. Fe-SOD and Cu/Zn-SOD activity is inhibited by high levels of $\mathrm{H}_{2} \mathrm{O}_{2}$ (Milone et al., 2003). Moreover, $\mathrm{H}_{2} \mathrm{O}_{2}$ inactivates biphophates enzymes in Calvin cycle which decreases $\mathrm{CO}_{2}$ fixation (Yamazaki et al., 2003). Regarding the Mg roles in activating RuBP-Car, ATP-ases and decreases of ROS-scavenger mechanisms under Mg deficiency, ROS accumulate in plant cells and oxidative stress occurs. The balance of the enzymes related to ROS scavenging mechanisms and non-accumulation of ROS is one of the 
indices expressing non-occurrence of oxidative stress. The results showed that SOD/APX $+\mathrm{GPX}+\mathrm{CAT}$ ratio increased under $\mathrm{Mg}$ deficiency. The ratio suggests that production rate of $\mathrm{H}_{2} \mathrm{O}_{2}$ by SOD is faster than its reduction by the scavenging enzymes. However, $\mathrm{H}_{2} \mathrm{O}_{2}$ is not produced just by SOD. The imbalance of $\mathrm{H}_{2} \mathrm{O}_{2}$ producing and scavenging would cause this toxic metabolite to accumulate in cells.

Total-SOD activity did not vary significantly as a result of the lack of Mg compared with control. Furthermore, MDA content and cell death was enhanced at Mg deficiency, too. These indexes indicated that oxidative stress occurred because $\mathrm{Mg}$ is an exceptional element in plant cell metabolism (Cakmak and Kirkby, 2008). Therefore, the produced $\mathrm{O}_{2}{ }^{-}$at cell metabolism is higher than increase in total-SOD activity under lack of $\mathrm{Mg}$ condition. As a result, $\mathrm{O}_{2}{ }^{-}$and $\mathrm{H}_{2} \mathrm{O}_{2}$ will produce highly toxic and reactive $\mathrm{HO}$ radical by Haber-Weiz reaction (Edreva, 2005). Tewari et al. (2005) reported that under Fe deficiency conditions, SOD, POX and CAT activities were decreased and in consequence $\mathrm{O}_{2}{ }^{-}$and $\mathrm{H}_{2} \mathrm{O}_{2}$ accumulated in plant cells. In these situations Haber-Weiz reaction does not run and this leads to low production of hydroxyl radicles and hence minimum oxidative stress.

The results displayed that the content of chlorophyll (Chl) decreased under Mg deficiency condition. The same result was reported by Cakmak and Marschner (1992). The reason is that Mg chelatase uses Mg-ATP to incorporate Mg into protoporphyrin XI structure and so be transformed (Cakmak and Marschner, 1992, Cakmak and Kirkby, 2008). Protoporphyrin XI is a highly toxic metabolite which is accumulated under Mg deficiency condition (Cakmak and Kirkby, 2008).

\section{Conclusions}

It can be concluded that $\mathrm{Mg}$ is a key element for cell metabolism and the deficiency of it leads to inactivities in critical metabolic points such as $\mathrm{CO}_{2}$ fixation, carbohydrate up-loading to phloem, ATP-ases activity. Increase in ROS production and/or accumulation of protoporphyrin XI are the direct results of Mg-deficiency. The increase in ROS production and their accumulation targets antioxidant enzymes involved in defense mechanisms, debilitating these enzymes. All these factors put together, leads to increased cell damage and high occurrence of cell programmed death.

\section{Acknowledgement}

The reported study was supported and financially backed by research chancellorship at Tabriz University.

\section{References}

Aebi, H. (1984). Catalase in vitro. Method of Enzymology, 105, 121-126.

Baker, C.J. and Mock. N.M. (1994). An improved method for monitoring cell death in cell suspension and leaf disk assay using Evans blue. Plant Cell Tissue Organ Culture, 39, 7-12.

Beak, K.H. and Skinner, D.Z. (2003). Alteration of antioxidant enzyme gene expression during cold acclimation of near-isogenic wheat lines. Plant Science, 165, 1221-1227.

Bradford, M. M. (1976). A rapid and sensitive method for the quantitation of microgram quantities of protein utilizing the principle of protein-dye binding. Analytical Biochemistry, 72, 248-254.

Breusegem, F. V., Vranova, E., Dat, J. F., and Inze, D. (2001). The role of active oxygen species in plant signal transduction. Plant Science, 161, 405-414.

Cakmak, I. and Kirkby. E. (2008). Role of magnesium in carbon partitioning and alleviating photooxidative damage. Physiologia Plantarum, 133, 692-704.

Cakmak, I. and Marschner, H. (1992). Magnesium deficiency and high light intensity enhance activities of superoxide dismutase, ascorbate peroxidase, and glutathione reductase in bean leaves. Plant Physiology, 98, 1222-1227.

Candan, N. and Tarhan, L. (2003). The correlation between antioxidant enzyme activities and lipid peroxidation levels in Mentha pulegium organs grown in $\mathrm{Ca}^{2+}, \mathrm{Mg}^{2+}, \mathrm{Cu}^{2+}, \mathrm{Zn}^{2+}$ and $\mathrm{Mn}^{2+}$ stress conditions. Plant Science, 163, 769-779.

Edreva, A. (2005). Generation and scavenging of reactive oxygen species in chloroplasts: A submolecular approach. Agriculture, Ecosystems and Environment, 106, 119-133.

Esfandiari, E. A., Shakiba, M. R., Mahboob, S. A., Alyari, H., and Toorchi, M. (2007). Water stress, antioxidant enzyme activity and lipid peroxidation in wheat seedling. Journal of Food, Agriculture \& Environment, 5, 48-53.

Gara, L. D., Pinto, M. C. and Tommasi, F. (2003). The antioxidant systems vis-á-vis reactive oxygen species during plant-pathogen interaction. Plant Physiology and Biochemistry, 41, 863-870. 
Grieve, C. and Garttan, R. (1983). Rapid assay for determination of water soluble quaternary ammonium componds. Plant and siol, 70, 303-307.

Hermans, C., Johnson, G. N. Strasser, R. J. and Verbruggen, N. (2004). Physiological characterization of magnesium deficiency in sugar beet: acclimation to low magnesium differentially affects photosystems I and II. Planta, 220, 344-355.

Hermans, C. and Verbruggen, N. (2005). Physiological characterization of Mg deficiency in Arabidopsis thaliana. Journal of experimental botany. 56: 2153-2161.

Jimenez, A., Hernandez, J. A., Pastori, G., Rio, L.A. D. and Sevilla, F. (1998). Role of the ascorbate-glutathione cycle of mitochondria and peroxisomes in the senescence of pea leaves. Plant Physiology, $118,1327-1335$.

Karabal, E., Yücel, M. and Öktem, H.A. (2003). Antioxidant responses of tolerant and sensitive barley cultivars to boron toxicity. Plant Science, 164, 925-933.

Kono, Y. and Fridovich, I. (1983). Inhibition and reactivation of Mn- catalase. The Journal of Biological Chemistry, 258, 13646-13468.

Kornyeyev, D., Logan, B. A., Allen, R. D. and Holadag, A. S. (2003). Effect of chloroplastic overproduction of ascorbate peroxidase on photosynthesis and photoproduction in cotton leaves subjected to low temperature photoinhibition. Plant Science, 165, 1033-1041.

Martinez, C. A., Loureiro, M. E., Oliva, M. A. and Maestri, M. (2001). Differential responses of superoxide dismutase in freezing resistant Solanum tuberosum subjected to oxidative and water stress. Plant Science, 160, 505-515.

Milone, M. T., Sgherri, C., Clijsters, H., and Navari-Izzo, F. (2003). Antioxidative responses of wheat treated with realistic concentration of cadmium. Environmental and Experimental Botany, 50, 265-276.

Mittler, R. (2002). Oxidative stress, antioxidants and stress tolerance. Trends in Plant Science, 7, 405410.

Quiles, M. J. and López, N. I. (2004). Photoinhibition of photosystems I and II induced by exposure to high light intensity during oat plant grown effects on the chloroplastic NADH dehydrogenase complex. Plant Science, 166, 815-823.

Sairam, R. K., Rao, K. V. and Srivastava, G. C. (2002). Differential response of wheat genotypes to long term salinity stress in relation to oxidative stress, antioxidant activity and osmolyte concentration. Plant Science, 163, 1037-1046.

Scandalios, J. G. (1993). Oxygen stress and superoxide dismutase. Plant Physiology, 101, 7-12.

Sergiv, I., V. and Alexieva, E. Karanov. (1997). Effect of spermine, atrazine and combination between them on some endogenous protective systems and stress markers in plants. Compt. Rend. Acad. Bulg. Sci., 51: 121-124.

Stewart, R. R. C. and Bewley, J. D. (1980). Lipid peroxidation associated aging of soybean axes. Plant Physiology, 65, 245-248.

Tewari, R. Kumar, P and Sharma, P. (2005). Signs of oxidative stress in the chlorotic leaves of iron starved plants. Plant Science, 169, 1037-1045.

Uchida, A., Jagendorf, A. T., Hibino, T., Takabe, T. and Takabe, T. (2002). Effects of hydrogen peroxide and nitric oxide on both salt and heat stress tolerance in rice. Plant Science, 163, 515-523.

Vaidyanathan, H., Sivakumar, P., Chakrabarsty, R. and Thomas, G. (2003). Scavenging of reactive oxygen species in NaCl-stressed rice (Oryza sativa L.)-differential response in salt-tolerant and sensitive varieties. Plant Science, 165, 1411-1418.

Velikova, V., Yordanov, I. and Edreva, A. (2000). Oxidative stress and some antioxidant systems in acid rain-treated bean plants. Protective role of exogenous polyamins. Plant Science, 151, 59-66.

Yamazaki, J, A, Ohashi, Y, Hashimoto, E, Negishi, S, Kumagai, T, Kubo, T, Oikawa, E, Maruta, Y, Kamimura. (2003). Effects of high light and low temperature during harsh winter on needle photodamage of Abies mariesii growing at the forest limit on Mt. Norikura in Central Japan. Plant Science, 165, 257-264.

Yoshimura, K., Yabute, Y., Ishikawa, T., and Shigeoka, S. (2000). Expression of spinach ascorbate peroxidase isoenzymes in response to oxidative stresses. Plant Physiology, 123, 223-233. 

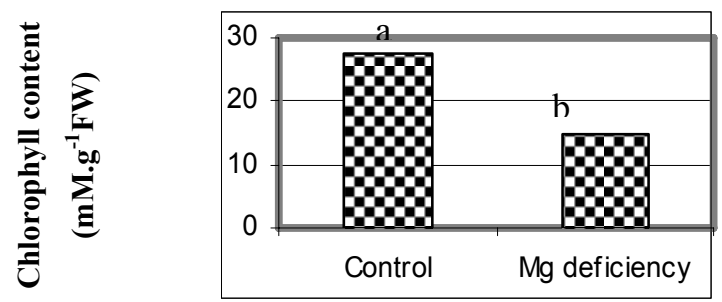

Figure 1. The effect of Mg deficiency on chlorophyll content. Different letters show significant difference

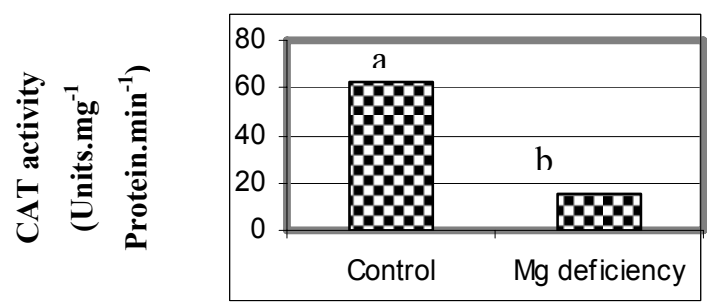

Figure 3. The effect of Mg deficiency on CAT activity. Different letters show significant difference
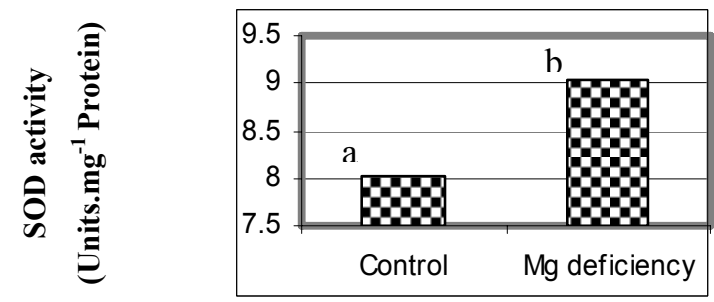

Figure 5. The effect of Mg deficiency on APX activity. Different letters show significant difference

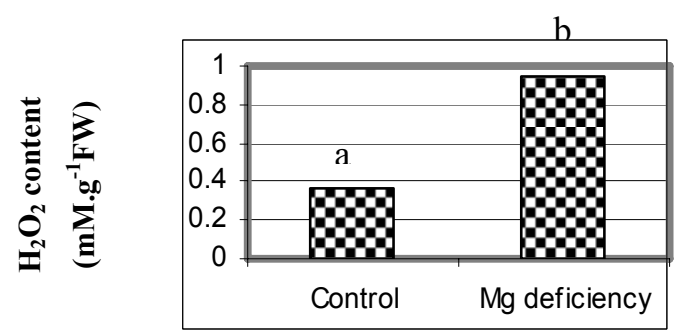

Figure 7. The effect of Mg deficiency on $\mathrm{H}_{2} \mathrm{O}_{2}$ content. Different letters show significant difference

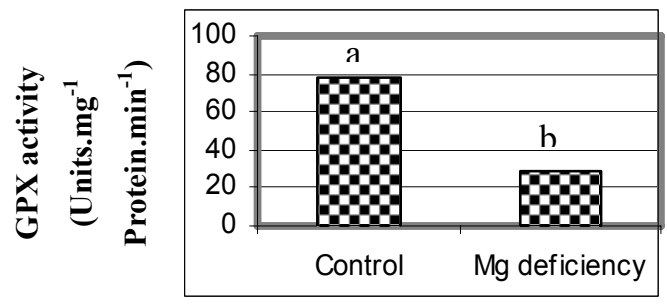

Figure 2. The effect of Mg deficiency on GPX activity.

Different letters show significant difference

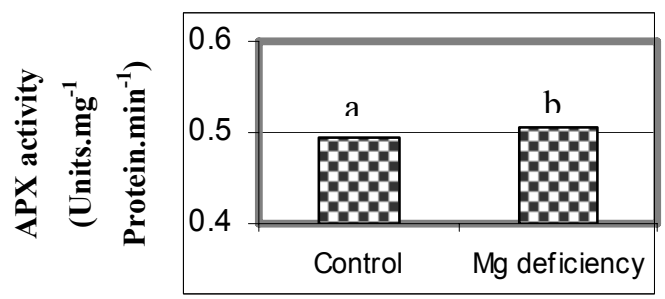

Figuer 4. The effect of Mg deficiency on APX activity.

Different letters show significant difference

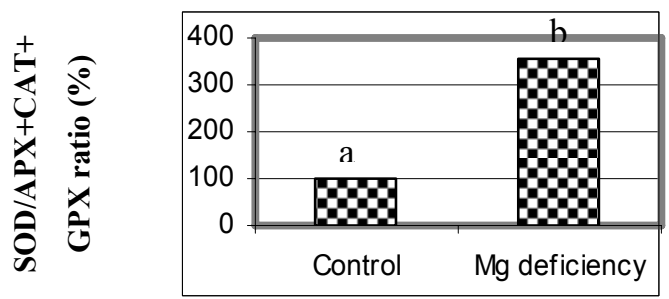

Figure 6. The effect of Mg deficiency on $\mathrm{SOD} / \mathrm{APX}+\mathrm{CAT}+\mathrm{GPX}$ ratio. Different letters show significant difference.

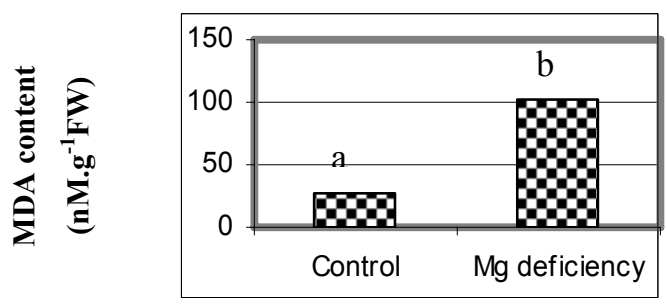

Figure 8. The effect of Mg deficiency on MDA content. Different letters show significant difference

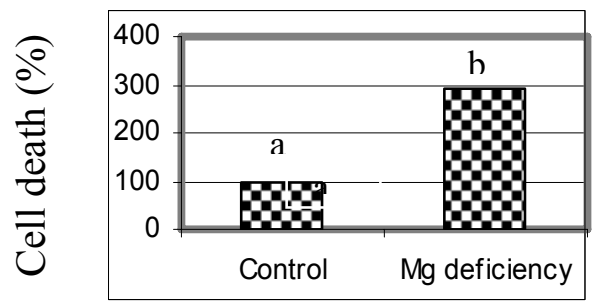

Figure 9. The effect of Mg deficiency on cell death.

Different letters show significant difference 